\title{
Validation of the gastroschisis experimental model and the influence of the mother's diet enriched with glutamine in the fetal morphology ${ }^{1}$
}

\author{
Cervantes Caporossi', Paulo Luiz Batista Nogueira" ${ }^{\text {II }}$, José Carlos Costa Marques ${ }^{\text {III }}$, Rafael Moraes de Assis ${ }^{\text {IV }}$, José Eduardo de \\ Aguilar-Nascimento ${ }^{\mathrm{V}}$ \\ IPhD, Associate Professor, Division of Digestive Surgery, Department of Surgery, Federal University of Mato Grosso (UFMT), Cuiaba-MT, Brazil. \\ Conception, design, intellectual and scientific content of the study. \\ IFellow Master degree, Postgraduate Program in Health Sciences, UFMT, Cuiaba-MT, Brazil. Acquisition and interpretation of data, manuscript writing.

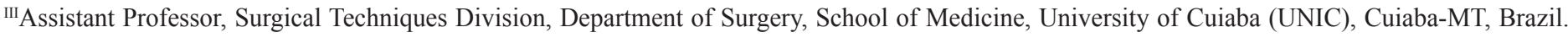 \\ Acquisition of data, statistical analysis. \\ ${ }^{\text {IV }}$ Graduate student, Faculty of Veterinary Medicine, UNIC, Cuiaba-MT, Brazil. Surgical procedures, acquisition of data. \\ ${ }^{\vee} \mathrm{PhD}$, Full Professor, Division of Digestive Surgery, Department of Surgery, UFMT, Cuiaba-MT, Brazil. Critical revision.
}

\begin{abstract}
PURPOSE: To validate the gastroschisis experimental model in female rats and the effects on the glutamine fetal morphology during pregnancy.

METHODS: Twelve pregnant rats Wistar were separated in two groups: Group I ( $\mathrm{n}=6$ rats, 71 fetuses) took glutamine and Group II ( $\mathrm{n}=6$ rats, 75 fetuses) took isocaloric supplementation. At the $18^{\text {th }}$ day of pregnancy, female rats were taken to hysterotomy and the fetuses which were selected for the act of gastroschisis were partially removed from the womb and by the laparotomy technique, the exclusion of the intestine was done. After that, fetuses were put in the womb cavity again and the rats' abdomen sutured. At the $21^{\text {st }}$ day of pregnancy, date before delivery, by $\mathrm{C}$-section ordinary animals and the ones with gastroschisis were removed and studied separately. The morphometrical parameters studied were the body weight (PC); the intestine weight (PI); the intestine length (CI) and its relations (PI/PC, PI/CI e PC-PI).
\end{abstract}

RESULTS: The intestine weight (PI) and the intestine length $(\mathrm{CI})$ were different in fetuses with gastroschisis $(\mathrm{p}<0.05)$, however no difference between the groups regarding supplementation with glutamine.

CONCLUSIONS: The gastroschisis experimental model is valid and reproducible. The nutritional therapy with glutamine did not change the morphometrical parameters.

Key words: Gastroschisis. Glutamine. Fetal Development. Rats. 


\section{Introduction}

Gastroschisis (GTS) is a congenital malformation of the abdomen characterized by a ventral defect on the right of the intact umbilical cord, with protrusion of the abdomen organs, generally the intestine ${ }^{1,2,3,12}$.

The intestine, outside the abdominal cavity is unprotected, having as consequences edema, thickening and a fibrin layer over the intestinal serosa taking it to a temporary dysfunction of its physiology ${ }^{4}$. Morbidity and mortality of the delay in the beginning of the intestine functioning associated to a rare prevalence of this disease, has motivated a variety of research centers into looking for solutions in studies using experimental animal models (sheep, rabbits, rats and chicken embryos $)^{5,6,14,15}$. One of the main objectives in the gastroschisis treatment is to prevent the harm to the fetus's intestine in small animals such as the rats because it is possible and has additional advantages like low costs, increased number of fetus per brood and for properly imitate the physiopathology of the human gastroschisis ${ }^{6}$.

The glutamine is an amino acid with an increased concentration of blood being especially used by the cells that show high numbers of renovation, like the enterocytes and leucocytes ${ }^{7,8,19}$. In addition, it is released in fetal circulation by placental synthesis and by maternal blood ${ }^{8,16}$. However, the objective of this study is to validate the gastroschisis experimental model in rats and evaluate the action of glutamine used during pregnancy over the body weight and the morphometrical changes of the fetuses' intestine.

\section{Methods}

The experimental procedures is agreement with the Ethical Principles for Animal Research established by the National Council for Control of Animal Experimentation (CONCEA) and approved by the institutional Committee for Ethics in the Use of Animals (Federal University of Mato Grosso) as a research project number 23108.046108/11-8.

Twelve female rats Wistar, 90 days weighing from 230 to $250 \mathrm{~g}$, coming from the central animal house of UFMT, were used in this study. The animals were separated into individual cages, a female and a male for mating. The couple was kept together for two nights. When checking the female vagina, the vaginal stain of sperm, the pregnancy is confirmed, classifying this as day zero of pregnancy and established as the probable brood day having the twenty second day subsequently. After mating, females are put in a quantity of two, per acrylic cage, having ration and water being offered to them ad libitum, and kept in an atmosphere of $24 \pm$ $1{ }^{\circ} \mathrm{C}$, relative humidity of $55 \%$ and light cycle from 07 to 19 hours. Animals were divided in two groups: a) Group I ( $n=6$ female rats, 71 fetuses), no glutamine supplementation; b) Group II ( $\mathrm{n}=6$ female rats, 75 fetuses) in which glutamine was supplemented during all pregnancy (Figure 1).

\begin{tabular}{|c|c|c|c|c|c|c|c|}
\hline \multicolumn{3}{|c|}{06 female rats (no glutamine) } & \multicolumn{4}{|c|}{06 female rats (used glutamine) } & \\
\hline \multicolumn{2}{|c|}{$\begin{array}{c}\text { Group I } \\
\text { N:71 fetuses }\end{array}$} & & & \multicolumn{2}{|c|}{$\begin{array}{c}\text { Group II } \\
\text { N:75 fetuses }\end{array}$} & & \\
\hline Control n:45 & \multicolumn{2}{|c|}{ Gastroschisis n:26 } & \multicolumn{2}{|c|}{ Gastroschisis n:29 } & \multicolumn{2}{|c|}{ Control n:46 } & \\
\hline & & \multicolumn{2}{|c|}{$\begin{array}{l}\text { Surgical procedure } \\
\text { (18 days) }\end{array}$} & \multirow{2}{*}{\multicolumn{4}{|c|}{$\begin{array}{l}\text { Morphometrical analysis } \\
\text { - Body weight, intestinal weight, intestinal } \\
\text { length } \\
\text { - Relation PI/PC; PI/CI; PC-PI }\end{array}$}} \\
\hline & & \multicolumn{2}{|c|}{$\begin{array}{l}\text { Data collection } \\
\text { (21 days) }\end{array}$} & & & & \\
\hline
\end{tabular}

FIGURE 1 - Study schedule.

The product used for glutamine supplementation was Glutamax $^{\circledR}$ (Vitafor, Brazil). To every five grams this product supplies an energetic value of twenty kilo-calories. The offered dosage in this study was of $2 \mathrm{gr} / \mathrm{kg}$ of weight/day. As the animals' average weigh before mating was of $250 \mathrm{gr}$, we offered a standard measure of enteral glutamine equivalent to $500 \mathrm{mg}$ per day. Therefore, each powder formulation equivalent to $500 \mathrm{mg}$ was diluted in $1 \mathrm{ml}$ of water and given as gavage once a day in the afternoon, in the supplementation constituent group during all pregnancy. Animals that did not make use of glutamine only received a standard isocaloric diet from the UFMT laboratory (Labina $^{\circledR}$, Ralston Purina, Brazil).

All animals went through surgery by the same researcher. At the $18^{\text {th }}$ day $^{6}$ of pregnancy the animal was taken to the procedure room and anesthetized with an intramuscular injection of ketamina- $\mathrm{S}^{\circledR} 50 \mathrm{mg} / \mathrm{ml}$ in the dosage of $1,26 \mathrm{ml} / \mathrm{kg}$ (ketamine hydrochloride, chemical products Cristalia) associated to Xylazine $2 \%, 10 \mathrm{mg} / \mathrm{ml}$ in a dosage of $0,42 \mathrm{ml} / \mathrm{kg}$ (Ronpun ${ }^{\circledR}$, Bayer).

A medium cut of $3 \mathrm{~cm}$ was done, exposing extra abdomen an uterine malformation. In the first moment a counting on the number of fetuses in the uterine malformation is done and it is also established which fetus will be used in the gastroschisis model.

To avoid premature birth or miscarriage, fetuses located in the uterine isthmus (cervix) and the last from the infundibulum area (oviduct) were not taken to surgery. The number sequence of the fetuses was done in a continuous way, counted from the proximal to the distal area in relation to the uterine cervix, in an increasing way, from the right horn to the left horn, next to this manipulation: control 1 -gastroschisis 2 - control 3 -gastroschisis 4 and so on (Figure 2) 


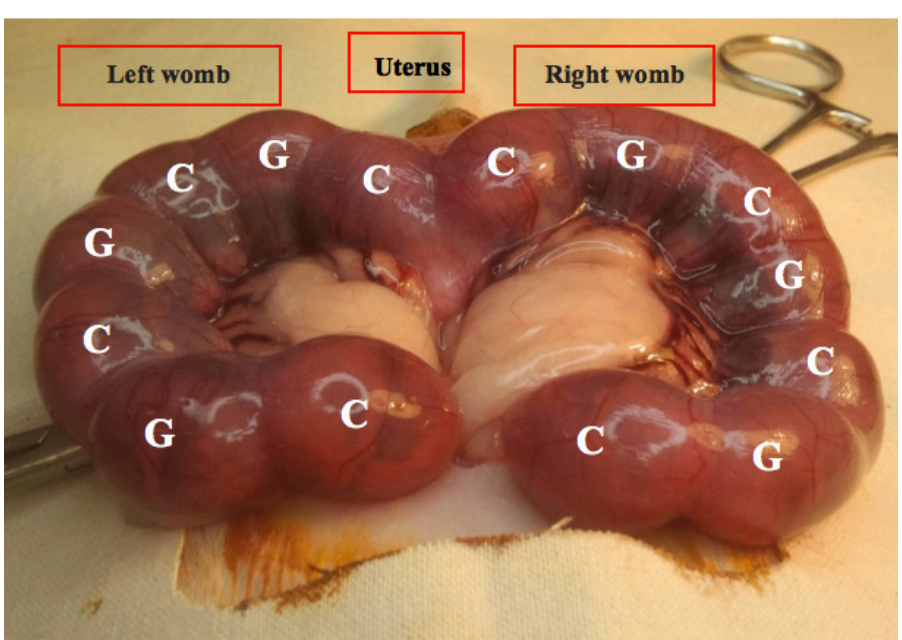

FIGURE 2 - Sequence manipulation of fetuses control and gastroschisis.

By using a surgical magnifying glass of 3,5x (Lupa Magnifying Lenses ${ }^{\circledR}$, Bio-art equipamentos odontológicos Ltda, Sao Carlos-SP) a hysterotomy was done in the right portion the chosen fetus had for the gastroschisis model. However, a round suture in the womb was made with a 6.0 mononylon line (Ethicon, Johnson \& Johnson Produtos Profissionais Ltda, Sao Paulo-SP) opening the womb's muscular wall and the amniotic membrane right after.

After that, a subtle manipulation of the fetus is done inside the womb in order to place the back paws into the front womb opening. With an anatomic surgical instrument the animal is carefully exposed to the umbilical cord level of implementation with the attention of not allowing its completely going out otherwise it is not possible to return (Figure 3).

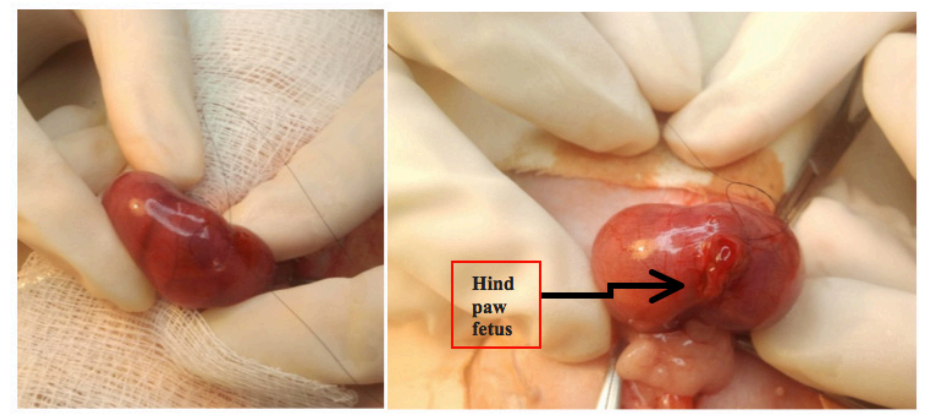

FIGURE 3 - Remove the fetus from the uterus, exposure of the animal's paw.

In this moment, the fetus is warmed with some spilling of saline to $38^{\circ} \mathrm{C}$. Identifying the implementation of the umbilical cord in the fetus' abdomen, a 3 millimeter paramedian cut to the right is done very carefully not to harm the umbilical vessels. A flexible untouched cotton stick (cotonete ${ }^{\circledR}$, Johnson \& Johnson Produtos Profissionais Ltda, Sao Paulo-SP) is used for a small abdominal pressure to help the expelling of the intestine content. The fetus is immediately given back to the womb and the suture is carefully done. At the end of the procedure a little aspiration in the amniotic cavity is done with a syringe of insulin and a volume of $0.3 \mathrm{ml}$ of saline is used to prevent oligohydramnios. After, the next fetus is considered as control, not being taken to a surgical procedure, following the sequence: "control-gastroschisis", according to what was mentioned before.

Next, the maternal laparotomy was closed and in the after surgery period, ration and water ad libitum were offered and the analgesia of the animals was done with two orogastric tubes and the use of drops of Dipirona $500 \mathrm{mg} / \mathrm{ml}$ (Anador ${ }^{\circledR}$, Boehringer Ingelheim do Brasil, SP) dosage of $10 \mathrm{mg} / \mathrm{kg}$.

At the $21^{\text {st }}$ Day of pregnancy rats were taken to a $\mathrm{C}$-section for the removal of the fetuses. The procedure was done in the same conditions as the ones described for the hysterotomy, taking the animals to the surgical room and using general anesthesia as mentioned before (the same dosage of Ketamine and Xylazine). The skin suture and the aponeurosis were removed and the abdominal cavity exposed.

The right horn of the womb was exposed and then one by one of the fetuses removed from the maternal womb. Each fetus is removed by a hysterotomy, the umbilical cord with the placenta is removed from the womb and then a lethal injection of ketamine is made through an occipital punch.

Then, the umbilical cord is connected to the abdominal wall and the body weighed in a precise scale (modelo Kern\& Sohn, Balingen, Germany). The dead fetus is put in prone position and little pins are put in the paws and cervical area so that it stays on the polystyrene board. (Poliestireno Expandido, EME indústria, Itapecerica da Serra-SP) (Figure 4).

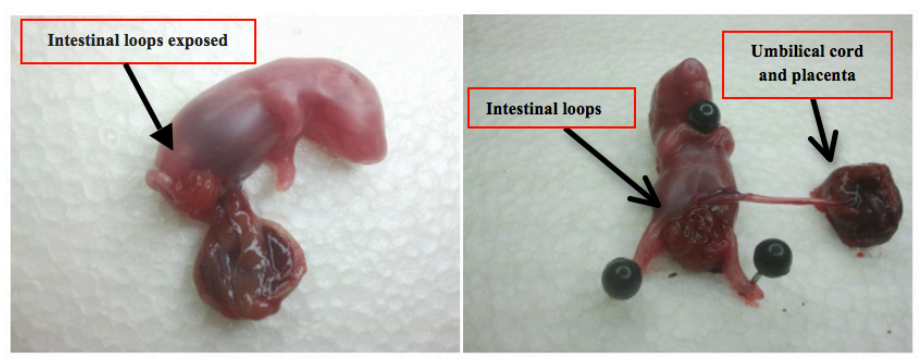

FIGURE 4 - Fetus removed from the uterus with the placenta of the rat. The intestinal loops exposed in the abdominal wall.

The fetus abdomen is carefully dissected with a medium cut and the intestine removed in parts, from the pyloric area to the superior rectum. The intestine part is weighed and by using 
a surgical magnifying glass the intestine is carefully dissected and straightened onto a polystyrene board. The intestine length is measured from the pylorus to the superior rectum over the peritoneum by using a caliper (Stainless Hardened $150 \mathrm{~mm}$, Guangdong China, Mainland). After the removal of the last fetus, the rat, still under the anesthesia effects was killed with a higher quantity of ketamine through an arterial aspiration.

Statistical data was organized in the Microsoft Office Excel 2010 program. All the variability measurements described were graphically represented in boxplot having defined the superior, inferior, medium limits, percentiles and quartiles. Such analyses described were done in Microsoft Office Excel 2010 and the statistical analysis in the Minitab 14 program. To compare both groups Analysis of variance (ANOVA) was used for the repeated measurements. The " $\mathrm{t}$ " test was used in the study referring to the mean in the groups. In all tests the trustness level chosen was fixed in 0.05 or $5 \%($ alpha $=5 \%)$ used for a rejection index of nullity hypothesis.

\section{Results}

Body weight

The mean of the body weight for the fetus in Group I (no glutamine) were: control (CI) $3.61 \mathrm{gr}( \pm 0.91)$ and gastroschisis (GTSI) $3.5 \mathrm{gr}( \pm 0.93)$. The mean of the body weight for the fetuses in Group II (with glutamine) were: control (CII) 3.53gr $( \pm 0.86)$ and gastroschisis (GTSII) de 3.59gr ( \pm 0.85$)$.

The comparative analysis of the body weight mean either in the group analysis that took glutamine (inter group) or the ones which went through intervention for the gastroschisis model (intra group) was similar ( $\mathrm{p}>0.05)$ (Figure 5).

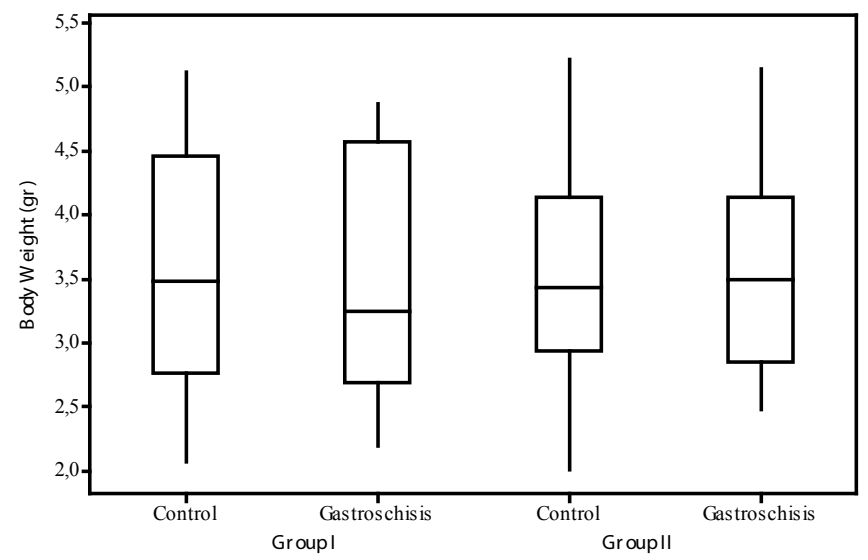

FIGURE 5 - Comparative of the fetuses' body weight according to the group. Group I-control; Group II-glutamine ( $\mathrm{p}>0.05)$.

\section{Intestine weight}

The intestine weight mean (PI) for the fetus in Group I were: control $(\mathrm{CI})$ : $0.10 \mathrm{gr}( \pm 0.04)$ and in gastroschisis (GTSI): 0.21 gr $( \pm 0.07)$. $(\mathrm{p}<0.05$; CI vs GTSI). The intestine weight mean (PI) for the fetus in group II were: CII: $0.11 \mathrm{gr}( \pm 0.04)$, and in GTSII:0.20gr $( \pm 0.07)$. $(\mathrm{p}<0.05$; CII vs GTSII). So the intra group statistical analysis (in the ones which went through surgery for the creation of the model) showed bigger intestine weight in the fetuses with gastroschisis, but no difference concerning the comparison between the groups. This data is represented in Figure 6.

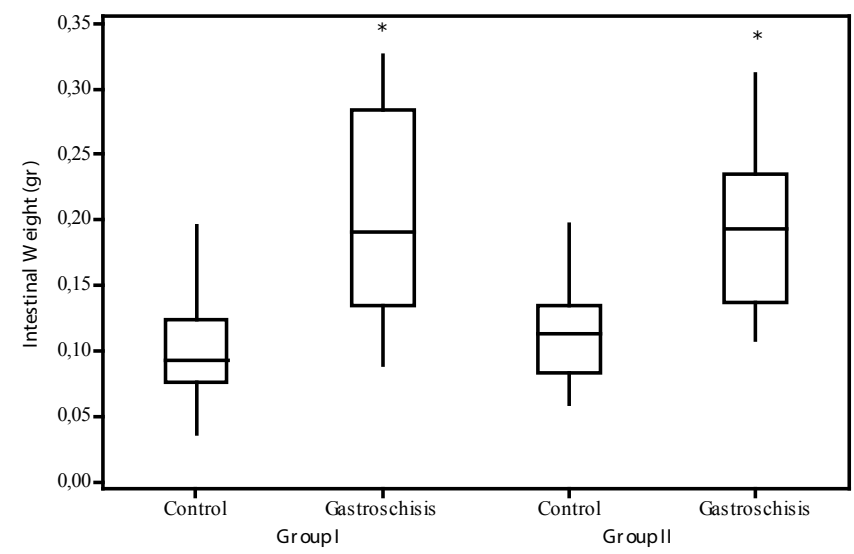

FIGURE 6 - Comparison of the intestine weight according to the group. Group I-control Group II-glutamine. ${ }^{*} \mathrm{p}<0.05$ Gastroschisis vs control in both groups.

\section{Intestine length}

The intestine length mean (CI) for the fetuses in Group I were: CI $125.41 \mathrm{~mm}( \pm 18.92)$ and in GTSI $72.63 \mathrm{~mm}( \pm 18.36)$. The intestine length was bigger in the control subgroup $(\mathrm{p}<0.05$; CI vs GTSI).

The mean for the fetuses in Group II were: CII $131.86 \mathrm{~mm}$ $( \pm 20.47)$ e no GTSII $77.66 \mathrm{~mm}( \pm 18.61)$ with a longer extension for fetuses with gastroschisis $(\mathrm{p}<0.05$; CII vs GTSII). However, when groups are compared one to another, there is no statistical difference. Data is shown right below in Figure 7.

\section{Intestine and body weight}

In the analysis of this variable, in Group I and Group II the mean found in the gastroschisis subgroup were bigger compared to the subgroup control. Group I [CI: $2.76( \pm 0.64)$ and GTSI: $5.84( \pm 1.35) \mathrm{p}<0.05]$ and Group II [CII: $3.28( \pm 0.92)$,e GTSII $5.62( \pm 1.65), \mathrm{p}<0.05]$. 


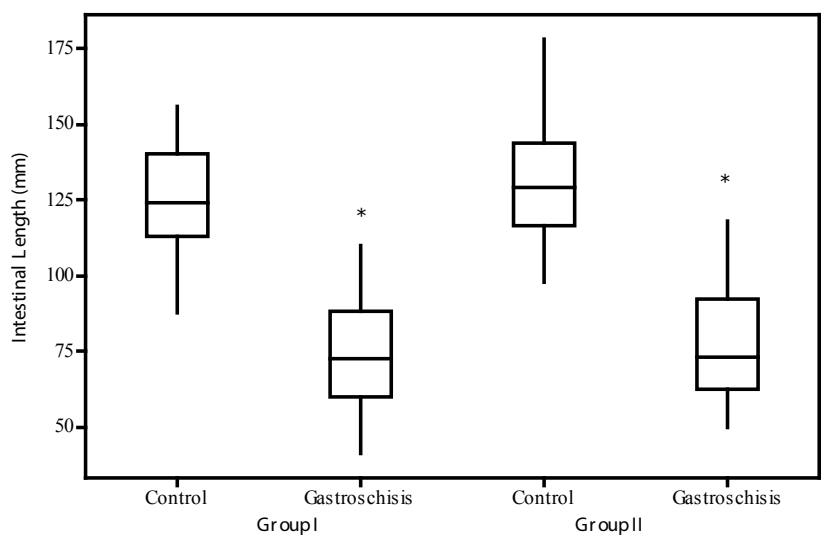

FIGURE 7: Comparison of the intestinal length according to the group. Group I-control Group II-glutamine. ${ }^{*} \mathrm{p}<0.05$ Gastroschisis vs control in both groups.

In the comparison of the relation intestine weight and body weight between the different groups, it was not seen a significant statistical variation. Data is shown in Figure 8.

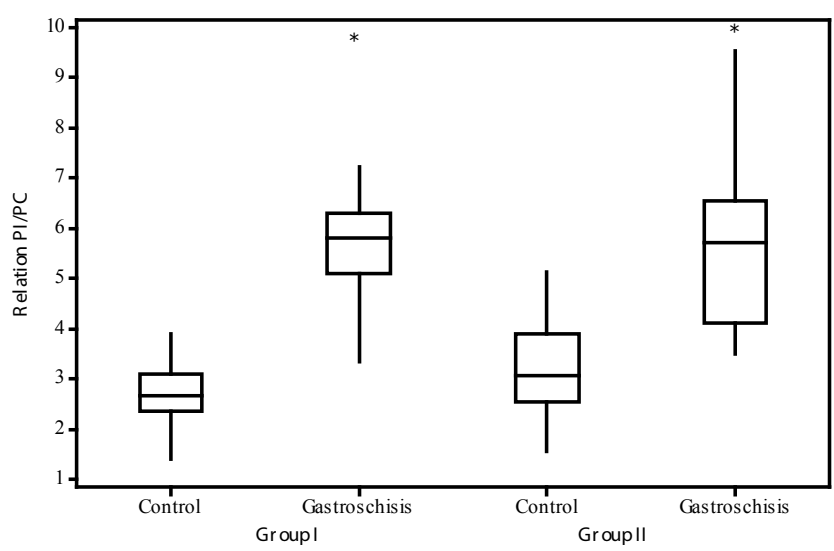

FIGURE 8 - Comparison between PI/PC according to the group. PI/ $\mathrm{PC}$ - relation intestine Body / body weight. Group I-control Group IIglutamine. $\mathrm{p}<0.05$ Gastroschisis vs control in both groups.

\section{Intestine body/intestine length}

In the relation between intestine weight and intestine length the mean found in Group I were: CI 79.05 ( \pm 23.68$)$, and GTSII: 287.10 ( \pm 85.50$)$. The relation intestine weight and intestine length PI/CI in the fetuses CI and GTSI showed a statistical difference $(p<0.05$; CIxGTSI).

The mean found in Group II in relation to PI/CI were CII $85.87( \pm 22.94)$ and GTSII $261.50( \pm 80.10)$. Comparing the changes intra group, an increase of the intestine weight and a decrease in the intestine length of the fetuses with gastroschisis $(\mathrm{p}<0.05$; CIIxGTSII).
The comparison of the relation $\mathrm{PI} / \mathrm{CI}$ between the different groups showed no influence of glutamine over this morphometrical measurement [CI do Group I 79.05 ( \pm 23.68$)$ while in Group II $85.87( \pm 22.94)]$ and in the fetuses which went through the gastroschisis model, with the influence of glutamine it was $287.10 \pm 85.50$ for group I x $261.50 \pm 80.10$ for group II, not showing a difference in this relation PI/CI of the fetuses in the different groups. Data is in Figure 9.

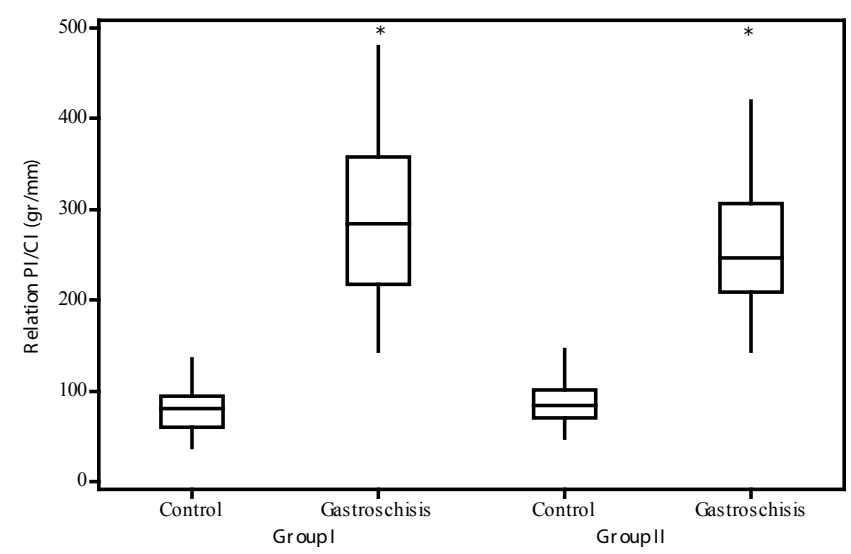

FIGURE 9 - Comparison between PI/CI according to the group. PI/CI - relation intestine weight / intestine length. Group I-control Group IIglutamine. $\mathrm{p}<0.05$ Gastroschisis vs control in both groups.

\section{Body weight - Intestine weight}

The mean with the difference of the body weight and the intestine weight (PC-PI) in group I were: CI: $3.51( \pm 0.88)$ varying from 2.00 to 4.92 and in GTSI: $3.30( \pm 0.87)$ varying from 2.06 to 4.59. The mean in this difference did not have a statistical level of significance ( $p>0.05$; CIxGTSI).

The mean for Group II following the difference of PCPI were: CII: $3.42( \pm 0.84)$ with a variation from 1.92 to 5.07 and GTS: $3.39( \pm 0.81)$ with a variation from 2.34 to 4.91 . In this analysis a statistical difference was not seen ( $p>0.05$; CIIxGTSII).

In the comparative study of the difference PCPI between the two groups, it was not seen the influence of glutamine in the different situations. In the control of group I C: $3.51( \pm 0.88)$ while in group II C:3.42 $( \pm 0.84)$ and in the fetuses which went through gastroschisis, over the influence of glutamine GTS:3.30 \pm 0.87 for group I vs GTS: $3.39 \pm 0.81$ for group II, not showing difference in PC-PI of the fetuses in the different groups. Data in the Figure below (Figure 10). 


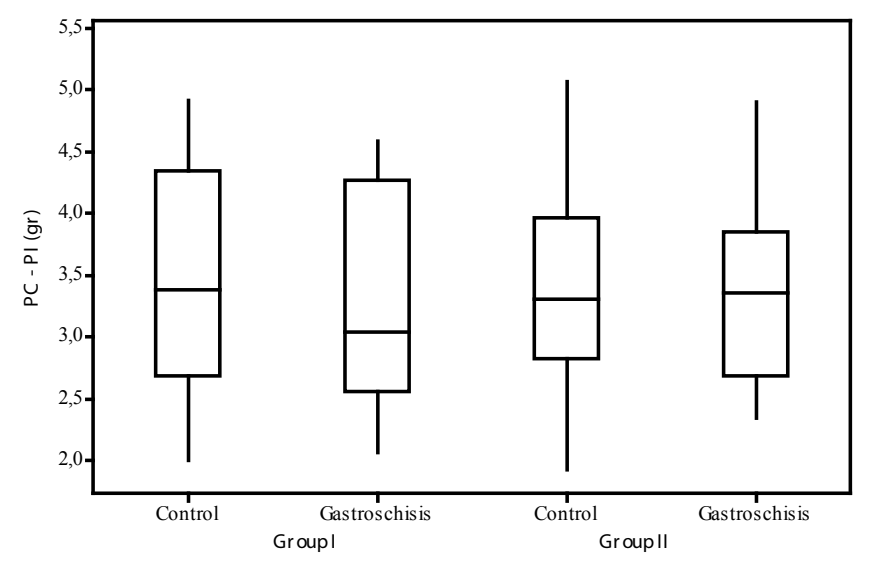

FIGURE 10 - Comparison between the difference of PC-PI according to the group. PC-PI: difference between body weight and intestine weight. Group I-control Group II-glutamine ( $\mathrm{p}>0.05)$.

\section{Discussion}

Though the gastroschisis survival rate is of $90 \%$ in several neonatal intensive therapy centers, its morbidity remains high due to the intestine dysfunction and the difficulty in the fetus's nutrition ${ }^{9-13}$.

So, periods of nutritional therapy are necessary, usually by parenteral nutritional therapy with oral diet being introduced later on. This attitude increases bad consequences after the closure of gastroschisis as risks of infection, metabolism disorder, growth delay and cholestatic liver disease $\mathrm{e}^{9,12}$.

However, all effort has to be done to search for alternatives in the early diagnosis and in all the treatment, especially in nutritional state to improve the morbidity and mortality rate. As it is a rare disease several research centers are motivated to look for experimental models in animals to reproduce this effect $t^{5,6,14,15}$.

In 2001, Correia-Pinto ${ }^{6}$ proposed a new model, in rats, that is being validated, adapted and developed in other research centers for the gastroschisis production and gradually used as an example in experiments to test medicaments and therapeutical interventions of this rare illness ${ }^{6}$. The models in rats it is possible to obtain a bigger number of fetus per brood, with the possibility of increasing the quantity of therapeutical interventions for each fetus studied.

The importance of this theme concerning our working field and the perspectives of having experimental studies that may contribute for the improvement of knowledge and treatment of gastroschisis motivated the validation of this experimental model in rats. Besides, the present study tried to associate the glutamine supplementation during the pregnancy in rats with fetuses which were taken to the gastroschisis model to study its action in the intestine morphology.
There is no evidence in the literature about the actual influence of glutamine supplementation during pregnancy, but many studies show that the transport and glutamine metabolism during fetal development exhibit unique characteristics, and the amino acid that has higher placental flow to the fetus being released in fetal circulation by placental synthesis and by the very blood circulation maternal ${ }^{16,18}$. There is a movement of glutamine to the fetus, its contribution over the exposed bowel loops of fetuses with experimental model of gastroschisis was our object of study in this work.

The glutamine supplementation in our research was of $2 \mathrm{gr} / \mathrm{kg}$ of weight/day, which is equivalent to a standard dosage of 500mg a day. In literature, the used dosages vary, not being possible to find a standard or a consensus about the proper data of glutamine in experimental animals. It is seen in the studies empiric supplementation in newborn, varying from 0.2 to $4 \mathrm{gr} / \mathrm{kg}$ of weight $/$ day ${ }^{17,19}$. This way, new researches have to be done to check if the used dosages in this study were not enough and in that way have not changed the macroscopic intestine parameters of the fetuses.

The variables of the result were based on morphometrical parameters for the validation of the gastroschisis model and also for the glutamine action. It represents an important limitation in the study, because lots of trophism characteristics and growth of the intestine mucus are observed in the intimacy only, as histological studies. However, intestine changes were clearly reproduced with gastroschisis, highlighting the shortening in the macroscopic aspect, the edema and the bigger weigh of the intestine and its relations. But about the glutamine effect in the variables studied (intestine macroscopic aspect), did not show efficiency.

The first variable checked was the body weight of the fetus. Studies show that newborn with gastroschisis show less body weight ${ }^{3,9,10,12}$. This observation is also described in the experimental models of gastroschisis in rats. However, in our study, it is described an average weigh of the fetuses which were taken to the gastroschisis model of $3.5 \mathrm{gr}$ and in those fetuses that received glutamine was found $3.59 \mathrm{gr}$, not revealing, this way, changes in the body weight between the different groups ( $\mathrm{p}=0.955)$.

The morphometrical analysis of the intestine weigh shows a statistical difference between the intestine weight of the fetuses control and gastroschisis in the different groups. This data reflects an important change that happens in the gastroschisis in humans referring to the edema and thickness of the intestine ${ }^{4}$, important fact for intestine dysfunction that happens after the birth of the new born ones. Another change seen in gastroschisis is the intestine length which is reduced in the fetuses that went through the experimental model compared to control ones ${ }^{6}$. There 
is a bigger growth of the intestine in the end of pregnancy mainly due to an increase of the protein synthesis and changes during pregnancy period may shorten the intestine ${ }^{2,3}$. Consequently, as glutamine is the main item of enterocytes, it was used during all the pregnancy period of time. We had an important statistical difference between the regular individuals (control) the ones that were taken to gastroschisis, with the shortening in the fetus GTS in group I and in group II. But with the supplementation of glutamine, body and intestine length measurements did not show statistical differences between the different groups $(\mathrm{p}=0.955)$.

A parameter was introduced in this study the ratio of intestinal to body weight, emphasizes the importance of intestine weight in the fetus's body structure. In the same group, comparing the fetus control and the gastroschisis ones, this relation was statistically meaningful for group I and for group II, showing the influence of intestine weight in the constitution of body weight of the gastroschisis fetus. However, in the ones supplemented with glutamine, this variable was similar to the control group (GTSI: $5.84 \pm 1.35$ vs GTSII: $5.62 \pm 1.65$ ).

When the analysis was done associating the previous variables according to Sbragia's work ${ }^{20}$, it is possible to see that these relations show changes of gastroschisis characteristics. In the relation intestine weight vs intestine length (PI/CI), again we had a change usually seen in gastroschisis which is the increase of the intestine weight unlikely proportional to the intestine length in the fetuses. The viscera exposure in the amniotic liquid causes a deep change in the structure of the intestine wall, just like an inflammatory process, causing a shortening and making it heavier than the control fetuses ${ }^{4}$. In literature these changes are described as a consequence of factors like the direct toxic action of the amniotic liquid over the intestine and the constriction of the intestine by the ostium of the abdominal wall of the hernial defect $^{2-4}$.In our work, this reversal was also particularly striking, with a statistical difference in control fetuses and gastroschisis.

The last parameter established in this study (PC-PI) seeks to exclude a possibility of interference in the body weight of the fetuses influenced by the bigger weigh of the intestine in the fetuses with gastroschisis, as seen in previous analysis. Introducing this parameter we can determine the actual weight of the fetus more clearly what has been observed in the literature where they have a retarded intrauterine growth and consequently lower weight corporal ${ }^{3,9,10,12}$. Despite the statistical evidence found in the smaller body weight among the fetuses with gastroschisis, in the analysis of body weight this difference was not established showing similar results to the analysis done before over the body weight of the fetuses.

\section{Conclusions}

The gastroschisis experimental model is valid and reproducible. The nutritional therapy with glutamine did not change the morphometrical parameters.

\section{References}

1. Sadler TW. The embryologic origin of ventral body wall defects. Semin Pediatr Surg. 2010;19(3):209-14.

2. Frolov P, Alali J, Klein MD. Clinical risk factors for gastroschisis and omphalocele in humans: a review of the literature. Pediatr Surg Int. 2010;26(12):1135-48

3. Holland AJ, Walker K, Badawi N. Gastroschisis: an update. Pediatr Surg Int. 2010;26(9):871-8.

4. Morrison JJ, Klein N, Chitty LS, Kocjan G, Walshe D, Goulding M, Geary MP, Pierro A, Rodeck CH. Intra-amniotic inflammation in human gastroschisis: possible aetiology of postnatal bowel dysfunction. Br J Obstet Gynaecol. 1998;105(11):1200-4.

5. Gandara CAT, Araújo ES, Motta UIC. Chicken embryo as an experimental model for the study of gastroschisis. Acta Cir Bras. 2008;23(3):247-52.

6. Correia-Pinto J, Tavares ML, Baptista MJ, Estevão-Costa J, Flake AW, Leite-Moreira AF. A new fetal rat model of gastroschisis: development and early characterization. J Pediatr Surg. 2001;36(1):213-6.

7. Novak F, Heyland DK, Avenell A, Drover JW, Su X. Glutamine supplementation in serious illness: a systematic review of the evidence. Crit Care Med. 2002;30(9):2022-9.

8. Borges MC, Rogero MM, Tirapegui J. Suplementação enteral e parenteral com glutamina em neonatos pré-termo e com baixo peso ao nascer. RBCF. 2008;44(1):13-23.

9. Huh NG, Hirose S, Goldstein RB. Prenatal intraabdominal bowel dilation is associated with postnatal gastrointestinal complications in fetuses with gastroschisis. Am J Obstet Gynecol. 2010;202(4):396.e1-6.

10. Garcia L, Brizot M, Liao A, Silva MM, Tannuri AC, Zugaib M. Bowel dilation as a predictor of adverse outcome in isolated fetal gastroschisis. Prenat Diagn. 2010;30(10):964-9.

11. Soares H, Silva A, Rocha G, Pissarra S, Correia-Pinto J, Guimarães H. Gastroschisis: preterm or term delivery? Clinics (Sao Paulo). 2010;65(2):139-42.

12. Tannuri AC, Sbragia L, Tannuri U, Silva LM, Leal AJ, Schmidt AF, Oliveira-Filho AG, Bustorff-Silva JM, Vicente YA, Tazima Mde F, Pileggi FO, Camperoni AL. Evolution of critically ill patients with gastroschisis from three tertiary centers. Clinics (Sao Paulo). 2011;66(1):17-20.

13. Orion KC, Krein M, Liao J, Shaaban AF, Pitcher GJ, Shilyansk J. Outcomes of plastic closure in gastroschisis. Surgery. 2011;Aug;150(2):177-85.

14. Stephenson JT, Pichakron KO, Vu L, Jancelewicz T, Jamshidi R, Grayson JK, Nobuhara KK. In utero repair of gastroschisis in the sheep (Ovis aries) model. J Pediatr Surg. 2010;45(1):65-9.

15. Albert A, Juliá V, Morales L, Rovira J, Sancho A, Bombi JA. Role of the amniotic fluid in gastroschisis. An experimental study. Cir Pediatr. 1992;5(1):12-6.

16. Neu J. Glutamine in the fetus and critically ill low birth weight neonate: metabolism and mechanism of action. J Nutr. 2001;131(9 Suppl):2585S-9S.

17. Potsic B, Holliday N, Lewis P, Samuelson D, DeMarco V, Neu J. Glutamine supplementation and deprivation: effect on artificially reared rat small intestinal morphology. Pediatr Res. 2002;52(3):430-6. 
18. Battaglia FC. Glutamine and glutamate exchange between the fetal liver and the placenta. J Nutr. 2000;130(4S Suppl):974S-7S.

19. Korkmaz A, Yurdakök M, Yiğit S, Tekinalp G. Long-term enteral glutamine supplementation in very low birth weight infants: effects on growth parameters. Turk J Pediatr. 2007;49(1):37-44.

20. Sbragia L, Schmidt AF, Moraes S, Bittencourt DG, Gonçalves FL, Pereira LA, Velloso LA. Inflammatory response in a rat model of gastroschisis is associated with an increase of NF-kappaB. Braz J Med Biol Res. 2010;43(2):160-5.

\section{Correspondence:}

Prof. Dr. Cervantes Caporossi

Avenida Fernando Corrêa da Costa, 2367

78060-900 Cuiaba-MT Brasil

Tel.: (55 65)3615-8000

caporosi@terra.com.br

Received: Nov 20, 2013

Review: Jan 21, 2014

Accepted: Feb 19, 2014

Conflict of interest: none

Financial source: none

${ }^{1}$ Research performed at Experimental Surgery Laboratory, Department of Surgery, School of Medicine, Federal University of Mato Grosso (UFMT), Cuiaba-MT. Part of Master degree thesis, Postgraduate Program in Health Sciences. Tutor: Cervantes Caporossi. 